\title{
Importance of Reperfusion Status after Intra-Arterial Thrombectomy for Prediction of Outcome in Anterior Circulation Large Vessel Stroke
}

\author{
Luuk Dekker a, b Victor J. Geraedts ${ }^{a}$ b Hajo Hund ${ }^{c}$ \\ Suzanne C. Cannegieter ${ }^{d}$ Raul G. Nogueira ${ }^{e}$ Mayank Goyal ${ }^{f}$ \\ Ido R. van den Wijngaard ${ }^{a, b}$ \\ ${ }^{a}$ Department of Neurology, Haaglanden Medical Center, The Hague, The Netherlands; \\ ${ }^{b}$ Department of Neurology, Leiden University Medical Center, Leiden, The Netherlands; \\ 'Department of Radiology, Haaglanden Medical Center, The Hague, The Netherlands; \\ ${ }^{\mathrm{d}}$ Department of Clinical Epidemiology, Leiden University Medical Center, Leiden,

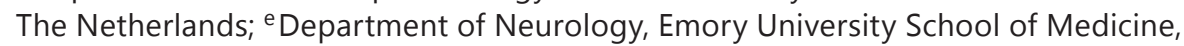

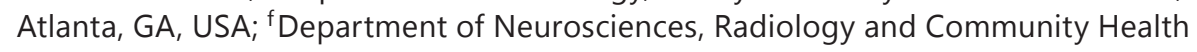 \\ Services, University of Calgary, Calgary, AB, Canada
}

\section{Keywords}

Ischemic stroke · Intra-arterial thrombectomy · Prognosis · Predictor · Reperfusion

\begin{abstract}
Background: Reperfusion status after intra-arterial thrombectomy (IAT) is a critical predictor of functional outcome after acute ischemic stroke. However, most prognostic models have not included a detailed assessment of reperfusion status after IAT. Objective: The aim of this work was to assess the association between successful reperfusion and clinical outcome. Methods: Clinical, radiological, and procedural variables of patients treated with IAT were extracted from our prospective stroke registry. The association with functional outcome using the modified Rankin Scale (mRS) after 3 months was assessed using multivariable logistic regression. An extension of the modified TICI score, eTICI, was used to classify reperfusion status. The prognostic value of reperfusion status after IAT in addition to age, stroke severity, imaging characteristics, treatment with intravenous thrombolysis, and time from symptom onset to the end of IAT was assessed with logistic regression and summarized with receiver operating characteristic curves. Results: In total, 119 patients were included (mean age 66 years). In multivariable analysis, age $>80$ years (OR 6.8, 95\% CI 1.2-39.8), NIHSS at presenta-
\end{abstract}

L.D. and V.J.G contributed equally to the manuscript. 
tion $>15$ (OR 7.3, 95\% CI 2.3-23.5), and incomplete reperfusion status (eTICI score <2C; OR $10.3,95 \%$ CI 3.5-30.6) were the strongest predictors of a poor outcome (mRS 3-6). Adding reperfusion status to the model improved the prognostic accuracy (AUC 0.88, 95\% CI 0.910.94). Our results indicate a large difference between using an eTICI cutoff of $\geq 2 \mathrm{C}$ versus $\geq 2 \mathrm{~B}$ : a cutoff $\geq 2 \mathrm{C}$ improved the predictive value for a good clinical outcome (2C: positive predictive value, PPV, 0.78; 2B: PPV 0.32). Conclusion: Our results promote using reperfusion status for assessing prognosis in ischemic stroke patients treated with IAT. A model using eTICI $\geq 2 \mathrm{C}$ had greater PPV than eTICI $\geq 2 \mathrm{~B}$ and could improve prognostic accuracy.

(C) 2018 The Author(s)

Published by S. Karger AG, Basel

\section{Introduction}

Approximately 12 million people worldwide are annually diagnosed with ischemic stroke [1]. Functional outcome after a proximal intracranial occlusion of the anterior circulation may be improved by intra-arterial thrombectomy (IAT), which is currently widely implemented as the standard care for acute ischemic stroke [2-7].

Knowledge of prognostic factors improves evidence-based patient management. Information on prognosis is crucial to both patients and their family, and aids in determining appropriate rehabilitation programs. However, predicting outcome after ischemic stroke remains difficult due to its heterogeneous nature and the various factors affecting the disease course [8-18].

Patient selection for IAT has been studied extensively [2, 6-8], whereas prognostication after IAT is relatively understudied [8-11]. Previous studies designed prediction models for outcome after ischemic stroke; however, the degree of reperfusion status was often not accounted for [19-23].

This study aims to assess the prognostic value of reperfusion status, including an extension of the currently used modified TICI score (eTICI; extended Treatment in Cerebral Ischemia), in addition to other clinical and radiological characteristics on functional outcome in anterior circulation stroke patients treated with IAT.

\section{Methods}

Patients

All patients with any form of stroke admitted to the Haaglanden Medical Center, The Hague, are systematically documented. Patients diagnosed with ischemic stroke between April 2014 and November 2016 were extracted from this prospective registry for further analysis.

Inclusion criteria for this study were: prestroke modified Rankin Scale (mRS) $\leq 2$, proximal occlusion in the anterior circulation, and treatment with IAT. A proximal occlusion was defined as an occluded distal internal carotid artery (ICA), M1 or M2 segment of the middle cerebral artery, or A1 or A2 segment of the anterior cerebral artery with or without tandem occlusion of the ICA. Local guidelines stipulate intravenous thrombolysis (IVT) initiated within $4.5 \mathrm{~h}$ and IAT within $6 \mathrm{~h}$ after symptom onset $[6,7]$. However, exceptions could be made at the physician's discretion and therefore the time from stroke onset to treatment was not used as an exclusion criterion. Based on findings from previous prediction models for IVT and IAT [8-24], the following variables were extracted from the registry: age, prestroke mRS, National Institutes of Health Stroke Scale (NIHSS) at presentation, Alberta Stroke Program Early CT Score (ASPECTS) for early ischemic changes [12], the Tan score for collateral supply [15], treatment with IVT, time from symptom onset to the end of IAT (i.e., sheath from groin), reperfusion status assessed with the eTICI score, and functional outcome. The eTICI score ranges from grade 0 (no reperfusion) to grade 3 (complete reperfusion) and was assessed after intervention by digital subtraction angiography. Previously, a modified TICI (mTICI) score of 2B (reperfusion of more than half of the previously occluded target artery ischemic territory) or 3 was classified as successful. However, recent studies 


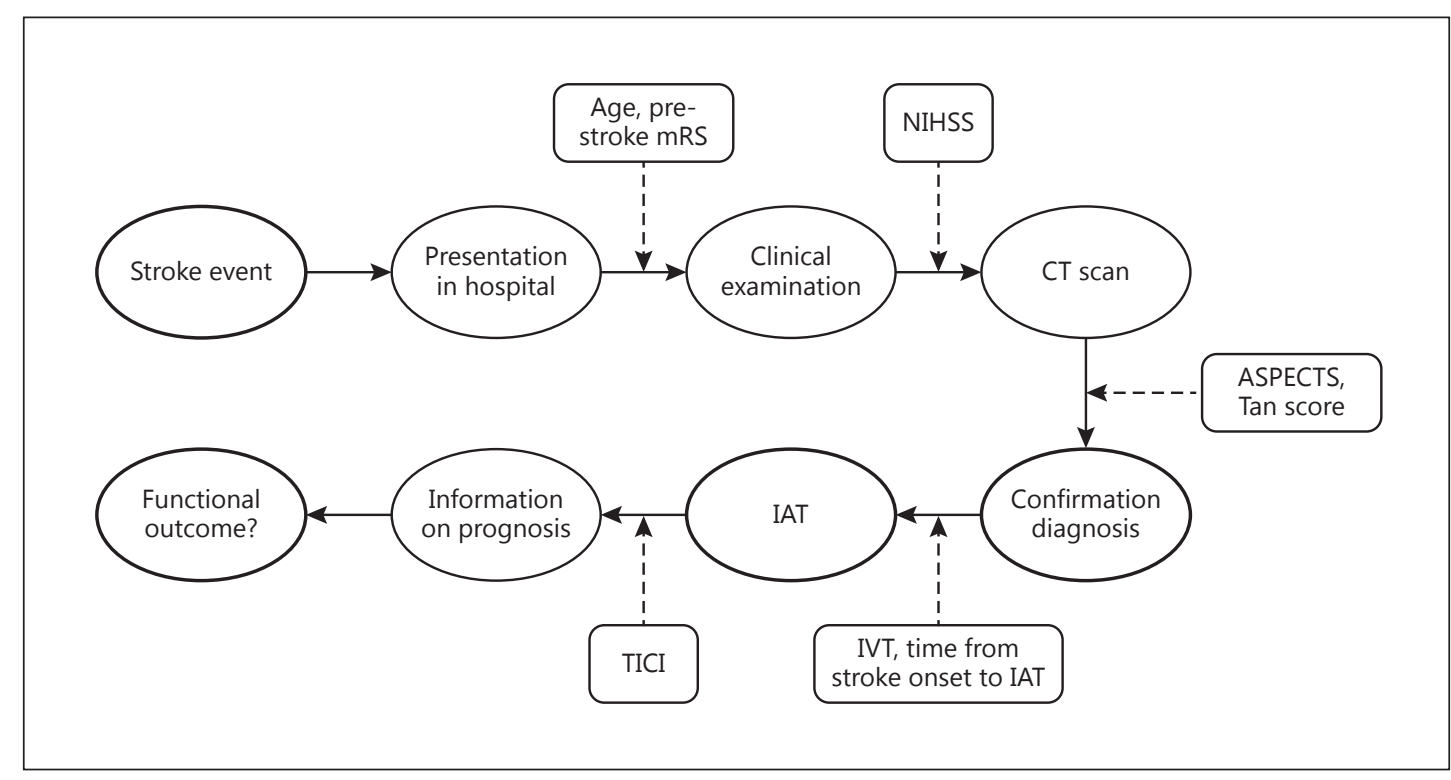

Fig. 1. Flowchart of stroke workup and feature selection.

have reported an extension of mTICI (i.e., eTICI), adding a 2C score which indicates a near complete perfusion except for slow flow in a few distal cortical vessels or presence of distal cortical emboli $[25,26]$. The effect of successful reperfusion on prognosis, either defined by eTICI $\geq 2 \mathrm{~B}$ or $\geq 2 \mathrm{C}$, was also assessed. The primary outcome was mRS at the 3-month follow-up. The $\mathrm{mRS}$ is a 7-point scale ranging from 0 (no symptoms) to 6 (death). A score above 2 points indicates functional dependence, i.e., poor functional outcome [27].

\section{CT Imaging Protocol}

Noncontrast CT and CT angiography (CTA) were evaluated by a stroke imaging researcher (H.H.). Patients were scanned using either a 16- or 64-slice CT scanner (Brightspeed S or Lightspeed VCT, respectively; General Electric Medical Systems, Hatfield, UK) with a tube voltage of $120 \mathrm{kV}$ and the gantry angled to the orbitomeatal line. The mean current was $335 \mathrm{~mA}$ and $100 \mathrm{~mA}$ for CT and CTA, respectively. For CTA, 50 $\mathrm{mL}$ of Visipaque iodine contrast material (General Electric Healthcare, Hatfield, UK) was injected intravenously and image acquisition was triggered automatically at the time of contrast passage through the aortic arch. Multiplanar reconstructions and 10-mm axial maximum intensity projection images were generated using Vitrea 6.8 (Vital Images, Minnetonka, MN, USA).

\section{Ethical Considerations}

The study protocol was approved by the local ethical committee of the Haaglanden Medical Center and the Medical Ethical Review Board of South-West Holland.

\section{Statistical Analysis}

Continuous variables are expressed as the mean with $95 \%$ confidence interval (CI) or median with interquartile range (IQR). Discrete variables were expressed as counts $(n)$ and percentages. Independent variables were dichotomized, with age at $>80$ versus $\leq 80$ years, NIHSS at presentation $>15$ versus $\leq 15$, use of IVT or not, ASPECTS $\leq 7$ versus $8-10$, Tan collateral score $<2$ versus $\geq 2$, time from symptom onset to the end of IAT $>360$ versus $\leq 360 \mathrm{~min}$, and eTICI score either $0-2 \mathrm{~A}$ versus $2 \mathrm{~B}-3$ or $0-2 \mathrm{~B}$ versus $2 \mathrm{C}-3$. Prestroke $\mathrm{mRS}$ was not included in the analyses due to its skewed distribution. These cutoff values are mostly based on previous studies $[12,16,17,24,28-30]$.

The association between aforementioned factors and poor clinical outcome after 3 months, i.e., $m R S>2$, was analyzed with univariate logistic regression models. Multivariate logistic regression models were subsequently computed with a forced entry autoregressive covariance matrix, applying a multiple-block structure reflecting the timeframe of the clinical process of stroke patients (Fig. 1). Given a sample size of 119 patients, we were confident of maintaining sufficient statistical power for a total of 7 predictors [31]. 
Dekker et al.: Importance of Reperfusion Status after Intra-Arterial Thrombectomy for Prediction of Outcome in Anterior Circulation Large Vessel Stroke

Table 1. Reasons for no IVT treatment

\begin{tabular}{lc}
\hline & $n$ \\
\hline Presentation at stroke center $>4.5$ h after onset & 15 \\
Use of anticoagulants & 6 \\
INR $>1.7$ & 3 \\
IVT in past 24-48 h & 3 \\
Recent surgery & 2 \\
Hypertension & 2 \\
Recent intracranial hemorrhage & 2 \\
Physicians choice for immediate IAT & 2 \\
Trauma & 1 \\
Recent stroke & 1 \\
Allergy to alteplase & 1 \\
\hline
\end{tabular}

IAT, intra-arterial thrombectomy; IVT, intravenous thrombolysis; INR, international normalized ratio.

The timeline of ischemic stroke patients from presentation in the emergency department up to treatment with IAT was systematically followed. Figure 1 depicts this process, including the time-points at which different variables were evaluated. Block 1 included age as the baseline characteristic. Block 2 included the NIHSS score (clinical information collected at presentation). Block 3 included the ASPECTS and Tan collateral score reflecting radiological variables during the diagnostic phase. Block 4 included co-treatment with IVT and time from the onset of symptoms to the end of IAT. Finally, block 5 included reperfusion status using the eTICI score reflecting radiological outcome after IAT. Odds ratios (OR) with 95\% CI were calculated.

To determine the discriminative properties of our model, a receiver operating characteristic (ROC) curve was plotted to assess the area under the curve (AUC). SPSS software (version 22.0; IBM SPSS, Chicago, IL, USA) was used for the statistical analyses. A $p$ value $<0.05$ was considered significant.

\section{Results}

\section{Patients and Outcomes}

Overall, 119 patients treated with IAT fulfilled the inclusion criteria. The mean age was 65 years (range 20-94 years) and 59 (49.6\%) were female. The median NIHSS at presentation was 15 , median ASPECTS was 9, and 90 patients (75.6\%) had a good collateral supply. Eightyone patients (68.1\%) were additionally treated with IVT. The reasons for refraining from IVT are detailed in Table 1.

Successful reperfusion was achieved in 90 patients $(75.6 \%)$ with a mean time from symptom onset to the end of IAT of $339 \mathrm{~min}$. At the 3-month follow-up, 47 patients $(40.2 \%)$ had a good clinical outcome, 49 patients (41.1\%) were alive but had a poor clinical outcome, 21 patients $(17.9 \%)$ had died, and 2 patients were lost to follow-up. The demographic, clinical, radiological, and procedural characteristics are shown in Table 2.

\section{Univariate Analyses}

Predictors of poor clinical outcome at the 3-month follow-up were: age (OR 4.0, 95\% CI 1.1-14.7), NIHSS at presentation (OR 7.1, 95\% CI 3.0-16.7), and ASPECTS (OR 2.2, 95\% CI 1.0-4.7). Both the eTICI score with a cutoff $<2$ B (OR 10.4, 95\% CI 3.4-32.3) and with a cutoff $<2$ C (OR 11.4, 95\% CI 4.6-28.2) were strong predictors of a poor clinical outcome (Table 3).

\section{Multivariate Analyses}

In multivariate analyses, the reperfusion status was dichotomized at a cutoff $\geq 2 \mathrm{C}$ as this yielded a larger regression coefficient compared to a cutoff at $\geq 2 \mathrm{~B}$. Age (OR $6.8,95 \% \mathrm{CI}$ 
Interventional

Neurology

Table 2. Demographic, clinical, radiological, and procedural characteristics
Table 3. Univariate association between dichotomous predictors and poor clinical outcome www.karger.com/ine

Dekker et al.: Importance of Reperfusion Status after Intra-Arterial Thrombectomy for Prediction of Outcome in Anterior Circulation Large Vessel Stroke

\begin{tabular}{lc}
\hline & Total $(n=119)$ \\
\hline Age, years & $65.5 \pm 15.3$ \\
Female & $59(49.6)$ \\
History of ischemic stroke or TIA & $18(15.1)$ \\
NIHSS at presentation & $15(11-19)$ \\
Prestroke mRS $>2$ & $14(11.8)$ \\
Occlusion sites & \\
$\quad$ M1 & $68(57.1)$ \\
$\quad$ M2 & $13(10.9)$ \\
$\quad$ M3 & $2(1.7)$ \\
$\quad$ Intracranial ICA & $34(28.6)$ \\
MCA and ACA without ICA & $2(1.7)$ \\
Extracranial involvement of ICA & \\
$\quad$ No & $94(79.0)$ \\
Carotid occlusion or stenosis $>70 \%$ & $14(11.8)$ \\
$\quad$ Dissection & $7(5.9)$ \\
$\quad$ Pseudo-occlusion & $4(3.4)$ \\
ASPECTS & $9(6-10)$ \\
Tan collateral score $\geq 2$ & $90(75.6)$ \\
Treatment with IVT & $81(68.1)$ \\
Time from symptom onset to end of IAT, min & $339 \pm 180$ \\
Good clinical outcome (mRS $\leq 2)$ at 3-month follow-up & $47(40.2)$ \\
\end{tabular}

Data are presented as the mean $\pm \mathrm{SD}, n(\%)$, or median (IQR). ACA, anterior cerebral artery; ASPECTS, Alberta Stroke Program Early CT Score; eTICI, extended treatment in cerebral ischemia; IAT, intra-arterial thrombectomy; ICA, internal carotid artery; IVT, intravenous thrombolysis; MCA, middle cerebral artery; mRS, modified Rankin Scale; NIHSS, National Institutes of Health Stroke Scale.

\begin{tabular}{lclr}
\hline Variable & OR & $95 \%$ CI & $p$ value \\
\hline Age $>$ 80 years & 4.000 & $1.089-14.698$ & 0.037 \\
NIHSS at presentation $>15$ & 7.092 & $3.015-16.680$ & $<0.001$ \\
ASPECTS <8 & 2.220 & $1.039-4.744$ & 0.040 \\
Tan collateral score <2 & 2.006 & $0.762-5.282$ & 0.159 \\
Treatment IVT & 0.580 & $0.257-1.312$ & 0.191 \\
Time from onset to end of IAT & & & \\
$\quad<360$ min & 2.203 & $0.915-5.302$ & 0.078 \\
eTICI score <2B & 10.443 & $3.380-32.264$ & $<0.001$ \\
eTICI score <2C & 11.431 & $4.639-28.167$ & $<0.001$ \\
\hline
\end{tabular}

ORs (for poor clinical outcome) were computed using univariate logistic regression with a forced entry autoregressive covariance matrix. ASPECTS, Alberta Stroke Program Early CT Score; eTICI, extended treatment in cerebral ischemia; IAT, intra-arterial thrombectomy; IVT, intravenous thrombolysis; mRS, modified Rankin scale; NIHSS, National Institutes of Health Stroke Scale. 
Dekker et al.: Importance of Reperfusion Status after Intra-Arterial Thrombectomy for Prediction of Outcome in Anterior Circulation Large Vessel Stroke

Table 4. Multivariate association between dichotomous predictors and poor clinical outcome
Table 5. mRS score per eTICI score

\begin{tabular}{lclc}
\hline Variable & OR & \multicolumn{1}{l}{$95 \%$ CI } & $p$ value \\
\hline Age $>80$ years & 6.798 & $1.160-39.829$ & 0.034 \\
NIHSS at presentation $>15$ & 7.316 & $2.276-23.524$ & 0.001 \\
ASPECTS $<$ 8 & 0.901 & $0.291-2.787$ & 0.856 \\
TAN score <2 & 2.093 & $0.462-9.468$ & 0.338 \\
Treatment IVT & 0.516 & $0.167-1.596$ & 0.251 \\
Time from onset to end of IAT & & & \\
$\quad<360$ min & 0.172 & $0.699-7.420$ & 0.172 \\
eTICI score <2C & 10.324 & $3.483-30.597$ & $<0.001$ \\
\hline
\end{tabular}

ORs were computed using multivariate logistic regression with a forced entry autoregressive covariance matrix. ASPECTS, Alberta Stroke Program Early CT Score; eTICI, extended treatment in cerebral ischemia; IAT, intra-arterial thrombectomy; IVT, intravenous thrombolysis; mRS, modified Rankin scale; NIHSS, National Institutes of Health Stroke Scale.

\begin{tabular}{llc}
\hline eTICI score & $\begin{array}{l}\text { Good functional outcome } \\
\text { (mRS 0-2), } n\end{array}$ & $\begin{array}{l}\text { Poor functional outcome } \\
\text { (mRS 3-6), } n\end{array}$ \\
\hline 0 & 1 & 11 \\
1 & 2 & 6 \\
2A & 1 & 17 \\
2B & 12 & 25 \\
2C & 18 & 5 \\
3 & 13 & 5 \\
\hline
\end{tabular}

eTICI, extended treatment in cerebral ischemia; mRS, modified Rankin scale.

1.2-39.8), NIHSS at presentation (OR 7.3, 95\% CI 2.3-23.5), and eTICI score cutoff <2C (OR $10.3,95 \%$ CI 3.5-30.6) were significantly associated with a poor clinical outcome at 3 months (see Table 4). The ASPECT score, Tan collateral score, additional treatment with IVT, and time from symptom onset to the end of IAT procedure were not significantly associated with clinical outcome.

ROC analyses showed an AUC of a model without reperfusion status of 0.81 (95\% CI 0.75-0.89), including the variables age, NIHSS at presentation, ASPECTS, Tan collateral score, time of symptom onset to the end of IAT procedure, and additional IVT at admission. A model incorporating eTICI (cutoff $\geq 2$ C) led to an AUC of 0.88 (95\% CI 0.81-0.94). The likelihood ratio test for a model with an eTICI cutoff $\geq 2 \mathrm{C}$ versus a model without reperfusion status was $20.9(p<0.001)$.

\section{Reperfusion Status}

Eighteen out of $23(78.3 \%)$ patients with an eTICI of 2C had a good clinical outcome, whilst only 12 out of 37 (32.4\%) patients with an eTICI 2B score had a good clinical outcome. The positive predictive value (PPV) of eTICI 2C was 0.78; whilst the PPV of eTICI $2 \mathrm{~B}$ was 0.32 . The distribution of functional outcome versus reperfusion status is displayed in Figure 2 and Table 5. 
Fig. 2. Distribution of functional outcome per eTICI score. Good functional outcome/poor functional outcome: eTICI $0, n=1 / 11$; eTICI $1, n=2 / 6$; eTICI $2 \mathrm{~A}, n=$ 1/17; eTICI 2B, $n=12 / 25$; eTICI 2C, $n=18 / 5$; eTICI $3, n=13 / 5$.

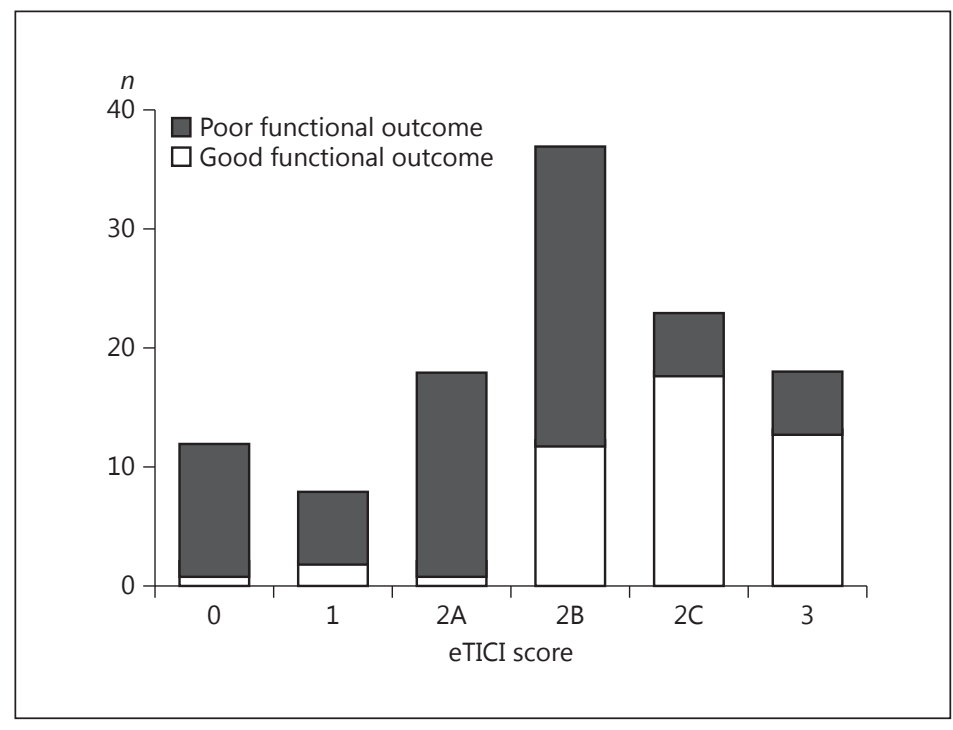

\section{Discussion}

Our study showed that reperfusion status after IAT has an additional prognostic value over baseline clinical and radiological characteristics, which has utility to provide patients and their families with a more accurate prognosis of functional dependence. Moreover, we found a substantial difference in clinical outcome between patients with a reperfusion status of eTICI 2B versus eTICI 2C, demonstrated by a large difference in PPV for good clinical outcome, favoring a cutoff at $\geq 2 \mathrm{C}$. It has been previously suggested that TICI scores incorporating $2 \mathrm{C}$ would better correlate with patient outcome and may positively influence an IAT procedure [25]. A previous study stated that using eTICI $\geq 2 \mathrm{C}$ as opposed to $\geq 2 \mathrm{~B}$ as the definition of successful reperfusion was a better predictor of outcome, especially of mRS 0-1 [26]. Our study results seem in line with those findings. Another recent study suggested that the outcome of patients with eTICI $2 \mathrm{C}$ is not clearly worse than patients with eTICI 3, whilst outcomes of both groups are significantly better than with eTICI 2B [32].

Older prediction score models include the Houston Intra-Arterial Therapy 2 (HIAT2) score, Totaled Health Risks in Vascular Events (THRIVE) score, Stroke Prognostication using Age and NIHSS (SPAN-100) index, iScore, and Pittsburgh Response to Endovascular therapy (PRE) score [19-23]. These models incorporate age and the severity of symptoms at presentation (NIHSS or Canadian Neurological Society score) and various variables such as prestroke mRS, ASPECTS, glucose at presentation, etiology of stroke, and medical history. However, previous studies have shown mTICI to be an important independent predictor of outcome [9-11] and this is not included in those models.

The patient characteristics of our study population, i.e., NIHSS at presentation, ASPECTS, rate of successful reperfusion status, and functional outcome, were in accordance with previous studies [2-4]. Most of the identified predictors were similar to those found in previous studies, i.e., advanced age, NIHSS at presentation, and successful revascularization $[9,11]$. Previous studies already demonstrate the importance of revascularization and highlight aiming for swift and complete revascularization when performing IAT [9-11, 24, 33]. In contrast to previous studies [2,3], ours did not show a significant influence of time from symptom onset to the end of IAT. However, this variable was dichotomized at $360 \mathrm{~min}$, which is the accepted time window for IAT. Patients treated outside this time window may have had favorable baseline parameters, thus possibly introducing selection bias. However, our findings 
suggest that patients may still benefit from IAT when performed more than $6 \mathrm{~h}$ after symptom onset and should not be excluded solely due to this time window, as previously demonstrated [34].

Recent results from the ESCAPE investigators showed that a neurological improvement in the first 2 days following a stroke predicted functional outcome with greater accuracy than other common variables [35]. Also, follow-up imaging was demonstrated to be a good predictor and possibly superior to mTICI scores [36, 37]. However, it would be beneficial for both patient and caregiver to have an early indication of prognosis to improve patient-caregiver communication and manage expectations.

With regards to radiological predictors, baseline CT ASPECTS was a significant predictor of outcome in univariate analysis, as demonstrated before [8, 9, 12-14, 17, 29]. However, in multivariate analysis, CT ASPECTS was not an independent predictor of outcome. A possible explanation could be the limited sample size in combination with the strong association between clinical stroke severity (NIHSS) and the extent of ischemic changes (ASPECTS) [38], which resulted in an insignificant predictive value of ASPECTS when clinical characteristics were also included. Moreover, recent studies have shown that CT ASPECTS and CT perfusion findings were not independent predictors when reperfusion status was included $[11,38]$. CT ASPECTS has limited inter- and intrarater reliability [39] and is less predictive than diffusionweighted imaging (DWI)-ASPECTS or CT perfusion [40-42]. However, recent studies using MRI DWI-ASPECTS also highlighted the importance of reperfusion status for the prediction of outcome $[33,43]$.

The limited prognostic value of the Tan collateral status in our cohort could be related to the use of single-phase CT instead of multiphase CTA. Single-phase CTA may underestimate the extent of the collateral status [18]. Some studies found that collateral status was not an independent predictor of outcome when other variables were taken into account $[14,38]$. Our results suggest that CT/CTA findings at presentation are of limited value for predicting clinical outcome and should be interpreted with caution $[8,42]$.

One of the strengths of this study is that all patients with a proximal occlusion in the anterior circulation in whom IAT was performed were included without using any additional imaging inclusion criteria, which increases the generalizability of our results. Other strengths include a near-complete follow-up and no other clinical selection criteria being used besides the exclusion of patients with a prestroke dependent functional status ( $m R S>2$ ).

A limitation of our work is that it is a single-center study with a limited number of patients. Also, no independent core facility for imaging analysis scored the reperfusion status. However, the imaging analyses were performed by 2 independent experienced stroke researchers who were blinded for functional outcome. Our findings should be verified on a larger scale, preferably in a multicenter setting. This could ultimately lead to a scoring system to predict outcome after IAT, preferably incorporating reperfusion status.

In conclusion, advanced age, higher NIHSS at presentation, and poor reperfusion status after IAT were the strongest predictors of a poor clinical outcome. These findings provide useful and early information on prognosis for both the patient and caregiver, and could ultimately lead to the development of a prediction algorithm designed for prognosis after IAT. Moreover, the introduction of an extension of the mTICI scoring system, i.e., eTICI, seems to improve diagnostic accuracy given the large difference in clinical outcome between eTICI $2 \mathrm{~B}$ and $2 \mathrm{C}$.

\section{Acknowledgements}

The authors wish to thank our local stroke nurses for the extensive and accurate registration of all stroke data in the registry. 
Dekker et al.: Importance of Reperfusion Status after Intra-Arterial Thrombectomy for Prediction of Outcome in Anterior Circulation Large Vessel Stroke

\section{Disclosure Statement}

The authors declare that they have no competing interests. No funding of any kind was received for the conduction of this study.

\section{Author Contributions}

I.R.v.d.W. conceptualized the study. L.D. and V.J.G. collected cases and drafted the manuscript. V.J.G. carried out the statistical analyses. H.H. and I.R.v.d.W. performed the imaging analysis. R.G.N., S.C.C., M.G., and I.R.v.d.W. contributed to critical revision of the manuscript. All authors helped in the revision of the manuscript and approved the final version.

\section{References}

$>1$ Krishnamurthi RV, Feigin VL, Forouzanfar MH, Mensah GA, Connor M, Bennett DA, Moran AE, Sacco RL, Anderson LM, Truelsen T, O'Donnell M, Venketasubramanian N, Barker-Collo S, Lawes CM, Wang W, Shinohara Y, Witt E, Ezzati M, Naghavi M, Murray C: Global and regional burden of first-ever ischaemic and haemorrhagic stroke during 1990-2010: findings from the Global Burden of Disease Study 2010. Lancet Glob Health 2013; 1:e259-e281.

-2 Goyal M, Menon BK, van Zwam WH, Dippel DW, Mitchell PJ, Demchuk AM, Davalos A, Majoie CB, van der Lugt A, de Miquel MA, Donnan GA, Roos YB, Bonafe A, Jahan R, Diener HC, van den Berg LA, Levy EI, Berkhemer OA, Pereira VM, Rempel J, Millan M, Davis SM, Roy D, Thornton J, Roman LS, Ribo M, Beumer D, Stouch B, Brown S, Campbell BC, van Oostenbrugge RJ, Saver JL, Hill MD, Jovin TG: Endovascular thrombectomy after largevessel ischaemic stroke: a meta-analysis of individual patient data from five randomised trials. Lancet 2016; 387:1723-1731.

-3 Bush CK, Kurimella D, Cross LJ, Conner KR, Martin-Schild S, He J, Li C, Chen J, Kelly T: Endovascular treatment with stent-retriever devices for acute ischemic stroke: a meta-analysis of randomized controlled trials. PLoS One 2016;11:e0147287.

4 Badhiwala JH, Nassiri F, Alhazzani W, Selim MH, Farrokhyar F, Spears J, Kulkarni AV, Singh S, Alqahtani A, Rochwerg B, Alshahrani M, Murty NK, Alhazzani A, Yarascavitch B, Reddy K, Zaidat O0, Almenawer SA: Endovascular thrombectomy for acute ischemic stroke: a meta-analysis. JAMA 2015;314:1832-1843.

5 Hansen CK, Christensen A, Ovesen C, Havsteen I, Christensen H: Stroke severity and incidence of acute large vessel occlusions in patients with hyper-acute cerebral ischemia: results from a prospective cohort study based on CT-angiography (CTA). Int J Stroke 2015;10:336-342.

-6 Powers WJ, Derdeyn CP, Biller J, Coffey CS, Hoh BL, Jauch EC, Johnston KC, Johnston SC, Khalessi AA, Kidwell CS, Meschia JF, Ovbiagele B, Yavagal DR: 2015 American Heart Association/American Stroke Association focused update of the 2013 guidelines for the early management of patients with acute ischemic stroke regarding endovascular treatment: a guideline for healthcare professionals from the American Heart Association/American Stroke Association. Stroke 2015;46:3020-3035.

7 Fiehler J, Cognard C, Gallitelli M, Jansen O, Kobayashi A, Mattle HP, Muir KW, Mazighi M, Schaller K, Schellinger PD: European recommendations on organisation of interventional care in acute stroke (EROICAS). Int J Stroke 2016;11:701-716.

-8 Venema E, Mulder M, Roozenbeek B, Broderick JP, Yeatts SD, Khatri P, Berkhemer OA, Emmer BJ, Roos Y, Majoie C, van Oostenbrugge RJ, van Zwam WH, van der Lugt A, Steyerberg EW, Dippel DWJ, Lingsma HF: Selection of patients for intra-arterial treatment for acute ischaemic stroke: development and validation of a clinical decision tool in two randomised trials. BMJ 2017;357:j1710.

-9 Ozdemir O, Giray S, Arlier Z, Bas DF, Inanc Y, Colak E: Predictors of a good outcome after endovascular stroke treatment with stent retrievers. ScientificWorldJournal 2015;2015:403726.

10 Soize S, Barbe C, Kadziolka K, Estrade L, Serre I, Pierot L: Predictive factors of outcome and hemorrhage after acute ischemic stroke treated by mechanical thrombectomy with a stent-retriever. Neuroradiology 2013;55: 977-987.

11 Yoon W, Kim SK, Park MS, Baek BH, Lee YY: Predictive factors for good outcome and mortality after stentretriever thrombectomy in patients with acute anterior circulation stroke. J Stroke 2017;19:97-103.

12 Barber PA, Demchuk AM, Zhang J, Buchan AM: Validity and reliability of a quantitative computed tomography score in predicting outcome of hyperacute stroke before thrombolytic therapy. ASPECTS Study Group. Alberta Stroke Programme Early CT Score. Lancet 2000;355:1670-1674.

13 Ryu CW, Shin HS, Park S, Suh SH, Koh JS, Choi HY: Alberta stroke program early CT score in the prognostication after endovascular treatment for ischemic stroke: a meta-analysis. Neurointervention 2017;12:20-30. 
Dekker et al.: Importance of Reperfusion Status after Intra-Arterial Thrombectomy for

14 Wroe NO, Palin RP, Patankar T, Bailey A, Igra M, Goddard T: Correlation between imaging markers and clinical and radiological outcome in hyperacute stroke patients undergoing thrombectomy. Eur J Minimally Invas Neurol Ther 2017:1707000407.

15 Tan IY, Demchuk AM, Hopyan J, Zhang L, Gladstone D, Wong K, Martin M, Symons SP, Fox AJ, Aviv RI: CT angiography clot burden score and collateral score: correlation with clinical and radiologic outcomes in acute middle cerebral artery infarct. Am J Neuroradiol 2009;30:525-531.

-16 van Seeters T, Biessels GJ, Kappelle LJ, van der Schaaf IC, Dankbaar JW, Horsch AD, Niesten JM, Luitse MJ, Majoie CB, Vos JA, Schonewille WJ, van Walderveen MA, Wermer MJ, Duijm LE, Keizer K, Bot JC, Visser MC, van der Lugt A, Dippel DW, Kesselring FO, Hofmeijer J, Lycklama ANGJ, Boiten J, van Rooij WJ, de Kort PL, Roos YB, van Dijk EJ, Pleiter CC, Mali WP, van der Graaf Y, Velthuis BK: The prognostic value of CT angiography and CT perfusion in acute ischemic stroke. Cerebrovasc Dis 2015;40:258-269.

17 Song D, Lee K, Kim EH, Kim YD, Kim J, Song TJ, Lee HS, Nam HS, Heo JH: Value of utilizing both ASPECTS and CT angiography collateral score for outcome prediction in acute ischemic stroke. Int J Stroke 2015;10:10181023.

-18 van den Wijngaard IR, Boiten J, Holswilder G, Algra A, Dippel DW, Velthuis BK, Wermer MJ, van Walderveen MA: Impact of collateral status evaluated by dynamic computed tomographic angiography on clinical outcome in patients with ischemic stroke. Stroke 2015;46:3398-3404.

19 Flint AC, Cullen SP, Faigeles BS, Rao VA: Predicting long-term outcome after endovascular stroke treatment: the totaled health risks in vascular events score. Am J Neuroradiol 2010;31:1192-1196.

20 Saposnik G, Kapral MK, Liu Y, Hall R, O’Donnell M, Raptis S, Tu JV, Mamdani M, Austin PC: IScore: a risk score to predict death early after hospitalization for an acute ischemic stroke. Circulation 2011;123:739-749.

21 Saposnik G, Guzik AK, Reeves M, Ovbiagele B, Johnston SC: Stroke prognostication using age and NIH stroke scale: SPAN-100. Neurology 2013;80:21-28.

$\checkmark 22$ Sarraj A, Albright K, Barreto AD, Boehme AK, Sitton CW, Choi J, Lutzker SL, Sun CH, Bibars W, Nguyen CB, Mir O, Vahidy F, Wu TC, Lopez GA, Gonzales NR, Edgell R, Martin-Schild S, Hallevi H, Chen PR, Dannenbaum M, Saver JL, Liebeskind DS, Nogueira RG, Gupta R, Grotta JC, Savitz SI: Optimizing prediction scores for poor outcome after intra-arterial therapy in anterior circulation acute ischemic stroke. Stroke 2013;44:3324-3330.

-23 Rangaraju S, Aghaebrahim A, Streib C, Sun CH, Ribo M, Muchada M, Nogueira R, Frankel M, Gupta R, Jadhav A, Jovin TG: Pittsburgh response to endovascular therapy (PRE) score: optimizing patient selection for endovascular therapy for large vessel occlusion strokes. J Neurointerv Surg 2015;7:783-788.

24 Yoo AJ, Simonsen CZ, Prabhakaran S, Chaudhry ZA, Issa MA, Fugate JE, Linfante I, Liebeskind DS, Khatri P, Jovin TG, Kallmes DF, Dabus G, Zaidat 00: Refining angiographic biomarkers of revascularization: improving outcome prediction after intra-arterial therapy. Stroke 2013;44:2509-2512.

25 Goyal M, Fargen KM, Turk AS, Mocco J, Liebeskind DS, Frei D, Demchuk AM: 2C or not 2C: defining an improved revascularization grading scale and the need for standardization of angiography outcomes in stroke trials. J Neurointerv Surg 2014;6:83-86.

26 Almekhlafi MA, Mishra S, Desai JA, Nambiar V, Volny O, Goel A, Eesa M, Demchuk AM, Menon BK, Goyal M: Not all "successful" angiographic reperfusion patients are an equal validation of a modified TICI scoring system. Interv Neuroradiol 2014;20:21-27.

27 van Swieten JC, Koudstaal PJ, Visser MC, Schouten HJ, van Gijn J: Interobserver agreement for the assessment of handicap in stroke patients. Stroke 1988;19:604-607.

28 Aviv RI, Mandelcorn J, Chakraborty S, Gladstone D, Malham S, Tomlinson G, Fox AJ, Symons S: Alberta stroke program early CT scoring of CT perfusion in early stroke visualization and assessment. Am J Neuroradiol 2007; 28:1975-1980.

29 Demchuk AM, Hill MD, Barber PA, Silver B, Patel SC, Levine SR: Importance of early ischemic computed tomography changes using ASPECTS in NINDS rtPA Stroke Study. Stroke 2005;36:2110-2115.

30 Hill MD, Demchuk AM, Goyal M, Jovin TG, Foster LD, Tomsick TA, von Kummer R, Yeatts SD, Palesch YY, Broderick JP: Alberta Stroke Program early computed tomography score to select patients for endovascular treatment: Interventional Management of Stroke (IMS)-III Trial. Stroke 2014;45:444-449.

31 Miller DE, Kunce JT: Prediction and statistical overkill revisited. Meas Eval Guid 1973;6:157-163.

-32 Tung EL, McTaggart RA, Baird GL, Yaghi S, Hemendinger M, Dibiasio EL, Hidlay DT, Tung GA, Jayaraman MV: Rethinking thrombolysis in cerebral infarction $2 \mathrm{~b}$ : which thrombolysis in cerebral infarction scales best define near complete recanalization in the modern thrombectomy era? Stroke 2017;48:2488-2493.

-33 Kim SK, Yoon W, Park MS, Heo TW, Baek BH, Lee YY: Outcomes are not different between patients with intermediate and high DWI-ASPECTS after stent-retriever embolectomy for acute anterior circulation stroke. Am J Neuroradiol 2016;37:1080-1085.

34 Jovin T, Nogueira R: 0-022 Dawn in full daylight (DWI or CTP assessment with clinical mismatch in the triage of wake up and late presenting strokes undergoing neurointervention). J Neurointerv Surg 2017;9:A13-A13.

-35 Sajobi TT, Menon BK, Wang M, Lawal O, Shuaib A, Williams D, Poppe AY, Jovin TG, Casaubon LK, Devlin T, Dowlatshahi D, Fanale C, Lowerison MW, Demchuk AM, Goyal M, Hill MD: Early trajectory of stroke severity predicts long-term functional outcomes in ischemic stroke subjects: results from the ESCAPE trial (Endovascular Treatment for Small Core and Anterior Circulation Proximal Occlusion with Emphasis on Minimizing CT to Recanalization Times). Stroke 2017;48:105-110. 


\section{Interventional Neurology}

36 Albers GW, Goyal M, Jahan R, Bonafe A, Diener HC, Levy EI, Pereira VM, Cognard C, Yavagal DR, Saver JL: Relationships between imaging assessments and outcomes in solitaire with the intention for thrombectomy as primary endovascular treatment for acute ischemic stroke. Stroke 2015;46:2786-2794.

-37 Bucker A, Boers AM, Bot JCJ, Berkhemer OA, Lingsma HF, Yoo AJ, van Zwam WH, van Oostenbrugge RJ, van der Lugt A, Dippel DWJ, Roos Y, Majoie C, Marquering HA: Associations of ischemic lesion volume with functional outcome in patients with acute ischemic stroke: 24-h versus 1-week imaging. Stroke 2017;48:1233-1240.

38 Zhu G, Michel P, Aghaebrahim A, Patrie JT, Xin W, Eskandari A, Zhang W, Wintermark M: Computed tomography workup of patients suspected of acute ischemic stroke: perfusion computed tomography adds value compared with clinical evaluation, noncontrast computed tomography, and computed tomography angiogram in terms of predicting outcome. Stroke 2013;44:1049-1055.

-39 Farzin B, Fahed R, Guilbert F, Poppe AY, Daneault N, Durocher AP, Lanthier S, Boudjani H, Khoury NN, Roy D, Weill A, Gentric JC, Batista AL, Letourneau-Guillon L, Bergeron F, Henry MA, Darsaut TE, Raymond J: Early CT changes in patients admitted for thrombectomy: intrarater and interrater agreement. Neurology 2016;87: 249-256.

40 McTaggart RA, Jovin TG, Lansberg MG, Mlynash M, Jayaraman MV, Choudhri OA, Inoue M, Marks MP, Albers GW: Alberta stroke program early computed tomographic scoring performance in a series of patients undergoing computed tomography and MRI: reader agreement, modality agreement, and outcome prediction. Stroke 2015;46:407-412.

-41 Bouslama M, Haussen DC, Grossberg JA, Dehkharghani S, Bowen MT, Rebello LC, Bianchi NA, Frankel MR, Nogueira RG: Computed tomographic perfusion selection and clinical outcomes after endovascular therapy in large vessel occlusion stroke. Stroke 2017;48:1271-1277.

-42 Schroder J, Thomalla G: A critical review of Alberta Stroke Program Early CT Score for evaluation of acute stroke imaging. Front Neurol 2016;7:245.

43 Costalat V, Lobotesis K, Machi P, Mourand I, Maldonado I, Heroum C, Vendrell JF, Milhaud D, Riquelme C, Bonafe A, Arquizan C: Prognostic factors related to clinical outcome following thrombectomy in ischemic stroke (RECOST study). Eur J Radiol 2012;81:4075-4082. 